\title{
Occupational type bronchial provocation tests: testing with soluble antigens by inhalation
}

\author{
M G HARRIES,* P S BURGE, AND I M O'BRIEN \\ From the Department of Clinical Immunology, Cardiothoracic Institute, London SW3, UK
}

\begin{abstract}
Thirty-seven patients with asthma or alveolitis thought to result from exposure to materials commonly encountered at their work were tested by inhalation of an aerosol of these materials. Twenty-four ( $65 \%$ ) developed an immediate asthmatic reaction, which was followed by a non-immediate reaction in 10, of whom six developed the signs and symptoms of alveolitis. Eighteen $(76 \%)$ patients with asthmatic reactions to test material were prick test positive to that material while only two out of 13 with a negative inhalation test were prick test positive $(15 \%)$. Precipitating antibody to test material was measured in 23 and was present in nine $(39 \%)$ of those with positive inhalation tests, and one $(12 \%)$ of those with negative tests. It was present in five of the six with a reaction in the gas exchanging portions of the lung.
\end{abstract}

The development of occupational asthma is serious for the patient for several reasons. Firstly, because it is not certain for how long the asthma persists after removal from exposure; secondly, in certain circumstances to be described lung damage may result; and, thirdly, because it often results in the patient losing his job. It is important, therefore, to make a precise aetiological diagnosis and for this reason bronchial provocation testing is carried out. Many occupational agents are insoluble in water and not suitable for use in a nebulised system. The materials reviewed here were of biological origin and were all soluble in water and so were suitable both for skin testing and for nebulisation. Different types of reaction result from inhalation tests depending on the type of material used and the immunological state of the patient. Asthmatic reactions may develop within one hour of testing (immediate reaction), within 12 hours (non-immediate), or during the night after challenge (nocturnal dip). ${ }^{12}$

Occasionally, other reactions may develop after exposure to antigen, characterised not by asthma but by fever, leucocytosis, malaise, and shortness of breath, sometimes accompanied by the appearance

*Present address: Department of Medicine, Guy's Hospital, London SE1 9RT.

Received 9 August 1979

Accepted 6 November 1979 of crackles in the lungs and occasionally by a fall in the diffusing capacity of carbon monoxide (transfer factor). Such reactions are thought to take place in the gas exchanging portions of the lungs and in many cases are associated with the presence of precipitating antibody. ${ }^{3}$ Asthmatic reactions resulting from repeated exposure to common environmental antigens have not been shown to result in lung damage, but similar exposure to those allergens causing reactions in the gas exchanging portions of the lung may ultimately result in the development of pulmonary fibrosis. ${ }^{4}$

\section{Patients and measurements}

Only patients with a history of respiratory illness worsening at work and improving at weekends or on holiday were selected for inhalation testing. In each case tests were performed to establish beyond reasonable doubt that the subject's respiratory illness was due to exposure to materials at work. All patients were admitted to hospital for testing, in order to treat any adverse reactions, to measure any non-immediate asthmatic reactions, and to record any nocturnal dips in forced expiratory volume in one second $\left(\mathrm{FEV}_{1}\right)$. Patients younger than 18 years or with an $\mathrm{FEV}_{1}$ of less than about 1.51 were not tested. Bronchodilator treatment was stopped before admission but those patients taking corticosteroids either by mouth or by inhalation remained on their usual regimen. 
$\mathrm{FEV}_{1}$ and $\mathrm{FVC}$ were measured with a dry wedge spirometer (Vitalograph). The patient was trained to reproduce recordings so that the best two were within 0.21 of each other. There were some problems with reproducibility since most of the patients studied were asthmatic and showed diurnal variation in FEV 1 . Where this variation exceeded $10 \%$ on any one day another day of control readings was added and if on both control days variation was related to time of day the patient was tested. If, however, variation in $\mathrm{FEV}_{\mathbf{1}}$ at a particular time varied by more than $10 \%$ from hour to hour or from day to day the patient was given salbutamol, $2 \mathrm{mg}$ every four hours by mouth, and challenge was performed with the patient taking this medication throughout. Variation in the nocturnal dip could not be controlled in this way, and in this case a direct comparison of the size of the dip on control day was made with days on which a challenge was performed.

Transfer factor (DLo) was divided by the alveolar volume (VA) to derive a constant (Kco), and these measurements were made in the plethysmograph twice daily at 1100 and 1600 , both on control days and after challenge. Blood for eosinophil count and serum precipitins was drawn in each case before inhalation testing. Prick tests with 23 common environmental allergen extracts (Bencards) were made. Patients giving a weal of $3 \mathrm{~mm}$ or more to any allergen and with a negative saline control were classified as atopic. Serum precipitins were measured by agar-gel double diffusion.

\section{Criteria for a positive inhalation test}

A fall in $\mathrm{FEV}_{1}$ of $15 \%$ or more compared with the control day and occurring within 24 hours of inhalation testing was regarded as a significant asthmatic reaction. A rise in temperature, malaise, leucocytosis, or the development of crackles in the lungs, or a fall in transfer factor of $15 \%$ or more within 24 hours of inhalation when compared with a day on which no challenge was given was arbitrarily regarded as a significant reaction in the gas exchanging portions of the lung or alveolitis.

\section{Materials}

Twenty-eight allergen extracts were used, 18 from mammalian sources, ten from vegetable sources, and two others (table 1). Vegetable antigens were defatted with ether for 24 hours then dried in a current of air. The filtrate was mixed 1/10 with Coca's solution-that is, $5 \mathrm{~g} \mathrm{NaCl}, 4 \mathrm{~g}$ phenol, $2.75 \mathrm{~g} \mathrm{NaHCO}_{3}$, and 1 litre distilled water, and extracted by stirring for one week. The supernatant was then clarified by filtration through filter paper

Table 1 Material given by nebulisation in 65 bronchial provocation tests showing the concentrations of test substance used on each occasion

\begin{tabular}{|c|c|c|c|c|c|c|}
\hline & & \multirow[t]{2}{*}{$\begin{array}{l}\text { No tested } \\
n=65\end{array}$} & \multicolumn{3}{|c|}{$\begin{array}{l}\text { Concentration of antigen in each } \\
\text { challenge }(\mathrm{mg} / \mathrm{ml})\end{array}$} & \multirow[t]{2}{*}{ Positive reactions } \\
\hline & & & $0 \cdot 1$ & $1 \cdot 0$ & 10 & \\
\hline \multirow{2}{*}{ Rat } & Serum & 5 & & 1 & 4 & 2 \\
\hline & Urine & 7 & 1 & 4 & 2 & 6 \\
\hline \multirow[t]{3}{*}{ Rabbit } & Serum & 3 & & & 3 & 1 \\
\hline & Urine & 2 & & 1 & 1 & 2 \\
\hline & Dander & 3 & & 2 & 1 & 二 \\
\hline \multirow[t]{3}{*}{ Mouse } & Serum & 3 & & 1 & 2 & 1 \\
\hline & Urine & 3 & 1 & 1 & 1 & 2 \\
\hline & Dander & 1 & & & 1 & - \\
\hline \multirow[t]{3}{*}{ Guinea pig } & Serum & 4 & & 1 & 3 & - \\
\hline & Urine & 4 & & 3 & 1 & 2 \\
\hline & Dander & 4 & & 1 & 3 & 2 \\
\hline Pig & Urine & 1 & & & & - \\
\hline \multirow[t]{2}{*}{ Budgerigar } & Serum & 2 & & & 3 & - \\
\hline & Feathers & 1 & & & 1 & - \\
\hline Cockatial & Serum & 1 & & & 1 & 1 \\
\hline \multirow{2}{*}{ Hen } & Serum & 2 & & & 2 & 1 \\
\hline & Feathers & 1 & & & 1 & - \\
\hline Pigeon & Serum & 3 & & 1 & 2 & 1 \\
\hline Barley extract & & 1 & & & 1 & 1 \\
\hline North American wheat extract & & 1 & & & 1 & 1 \\
\hline Hop extract & & 1 & & & 1 & 1 \\
\hline Mushroom extract & & 1 & & & 1 & 1 \\
\hline Pine extract & & 2 & & & 2 & - \\
\hline Micropolyspora faeni & & 5 & & & 5 & 3 \\
\hline Aspergillus clavatus & & 1 & & 1 & & 1 \\
\hline Merulius lachrymans & & 1 & & & 1 & 1 \\
\hline Gum acacia & & 1 & & & 1 & 1 \\
\hline Coccus cactus ${ }^{\mathrm{s}}$ & & 1 & & & 1 & 1 \\
\hline
\end{tabular}


(Whatman No 1) and passed through Seitz filter, then dialysed against running tap water in visking cellophane and freeze-dried for stock. Material for inhalation tests was made up freshly by diluting stock in Coca's solution at $0.1 \mathrm{mg} / \mathrm{ml}, 1.0 \mathrm{mg} / \mathrm{ml}$, or $10 \mathrm{mg} / \mathrm{ml}$. Samples for skin testing were made up in similar concentrations but mixed $50 \%$ with glycerol.

Animal urines were filtered through multipore diameter $0.5 \mu$ and sterilised by heating at $56^{\circ} \mathrm{C}$ for two hours before being freeze-dried for stock. Samples for both inhalation and skin tests were made up freshly in the same way as vegetable antigens. Animal serum was sterilised and made up $0.1 \%$, $1 \%$, and $10 \%$ in Coca's solution.

\section{Method}

Both test material and Coca's control were inhaled as an aerosol from a Wright's nebuliser with an oxygen flow rate of $8 \mathrm{l} / \mathrm{min}$ delivered to a tightfitting face mask with a rebreathing bag. FEV 1 and FVC were measured before testing and every five minutes for 30 minutes and then every 10 minutes for a further $\mathbf{3 0}$ minutes for the immediate reaction, then every hour for $\mathbf{1 2}$ hours for the non-immediate reaction and at 0600 for the nocturnal dip. The starting concentration of test material nebulised was that which gave a skin prick test reaction of $3 \mathrm{~mm}$ diam or less. Patients with negative skin tests were tested with a concentration no greater than $10 \mathrm{mg} / \mathrm{ml}$. Only one inhalation test was performed each day but at the same time each day- 0900 .

The test material was nebulised in the first instance for five minutes split into three periods; the first of one minute then two periods of two minutes, each separated by 10 minutes. If at any time the $\mathrm{FEV}_{1}$ fell by $15 \%$ or more the test was stopped. If by the next day the FEV 1 had not returned to pretest levels no further inhalations were given on that day either. If the $\mathrm{FEV}_{1}$ returned to normal or if no asthmatic reaction had occurred on the previous day then the concentration of test material was increased tenfold, and the same procedure was followed. If having been exposed to test material at a maximum concentration of $10 \mathrm{mg} / \mathrm{ml}$ for a total period of five minutes no reaction occurred on the next day the patient was given material at $10 \mathrm{mg} / \mathrm{ml}$ nebulised for 15 minutes, split into three periods of five minutes, each 10 minutes apart. Patients undergoing investigation for suspected "allergic alveolitis" also had Kco measured before and four and eight hours after testing and again on the morning of the next day. The patient's temperature was measured' every four hours during the day.

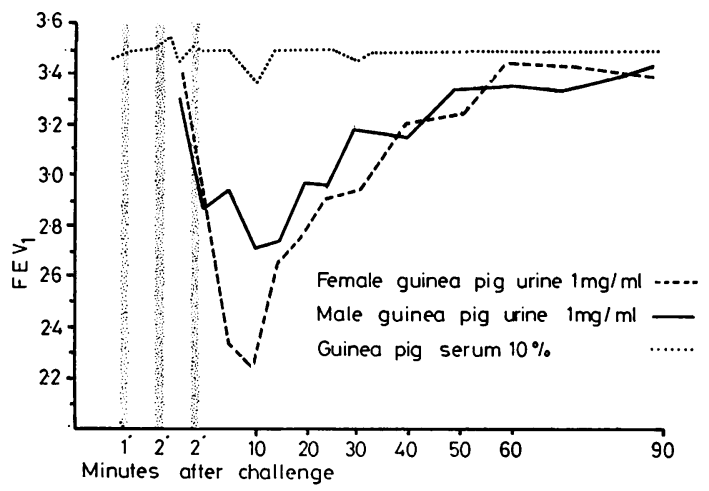

Fig 1 An immediate asthmatic reaction induced by inhalation of freeze-dried guinea pig urine for one minute at a concentration of $1 \mathrm{mg} / \mathrm{ml}$. No such reaction occurred after challenge with $10 \%$ serum. Allergen may be secreted in urine.

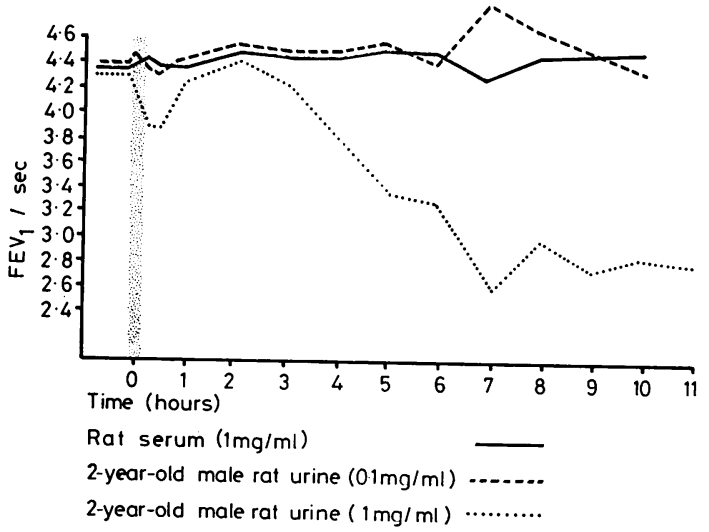

Fig 2 An immediate and non-immediate reaction induced by urine of a 2-year-old male rat at $1 \mathrm{mg} / \mathrm{ml}$ but not $0.1 \mathrm{mg} / \mathrm{ml}$. No such reaction occurs after nebulisation of rat serum at $1 \mathrm{mg} / \mathrm{ml}$.

\section{Results}

Thirty-seven patients ( 17 female, 20 male, age range 18-57 years) were given inhalation tests using an aerosol of material encountered at work. Asthmatic reactions developed in 24 patients, of whom six also developed alveolitis. One developed alveolitis without any asthmatic symptoms. All 24 gave immediate reactions (fig 1), and 10 of these also gave a non-immediate reaction (fig 2 ). In no case did a non-immediate reaction develop without a preceding immediate reaction (table 1). The mean fall in $\mathrm{FEV}_{1}$ in the immediate reaction was $26 \%$ $(38 \%-16 \%)$ and in the non-immediate reaction $23 \%(44 \%-16 \%)$. Only seven out of 37 tested 


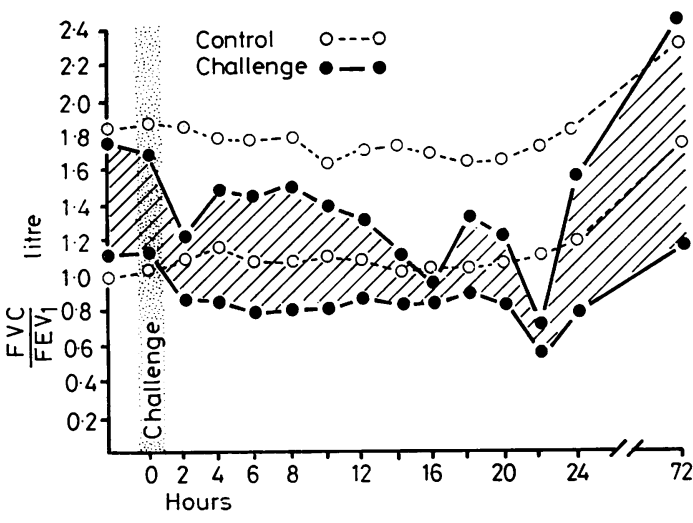

Fig $3 F E V_{1}$ and FVC are plotted separately. Exposure to cockatial serum results in a fall in both $F E V_{1}$ and $F V C$, maximal 22 hours after challenge (0700) but ratio of $F E V_{1} / F V C$ changes very little. Patient developed breathlessness but did not wheeze. No such reaction occurs after exposure to saline control.

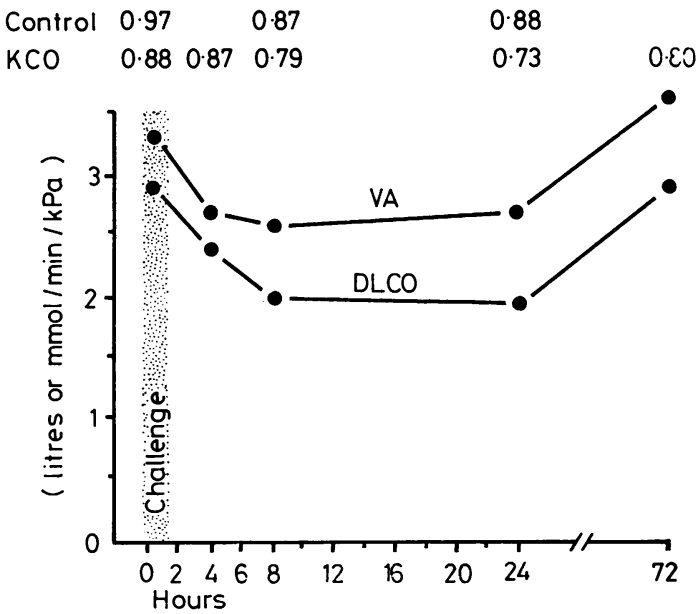

Fig 4 Simultaneous measurement of $V A$ and DLCO in same patient after bronchial provocation with cockatial serum. Fall in DLCO is largely due to concomitant fall in $V A$. developed a reaction more than twice that which was regarded as significant-that is, greater than $30 \%$ - and none of these patients required specific treatment. There was no correlation between the size of the immediate reaction and of the nonimmediate reaction that followed it. Twelve of the 37 subjects developed no asthma.

Seven subjects developed signs and symptoms characterised by malaise, tightness in the chest, tachycardia, or crackles in the lungs on auscultation. Two patients also became depressed and tearful. A diagnosis of allergic alveolitis was confirmed on lung biopsy in three cases and by a fall in transfer factor of greater than $15 \%$ compared with control in three others (figs 3 and 4). The remaining patient developed malaise but with no fall in transfer factor.

Of the 24 subjects with asthmatic reactions, 16 $(66 \%)$ were atopic. Eighteen $(75 \%)$ were prick test positive to the test allergen. In the 13 patients who did not develop asthma only two were prick test positive to test antigen (table 2 ). In the seven subjects with signs and symptoms of alveolitis four were atopic and three of these were prick test positive to test antigen. Of the remaining three who were non-atopic, two were prick test positive to test antigen. One reacted to inhalation of cockatial serum and two reacted to extract of Micropolyspora faeni.

Serum for estimating precipitating antibody was made in 23 of the 37 subjects, in each case before inhalation testing; eight had antibody against the test antigen. Of eight subjects who had no asthmatic reaction, only two had antibody. Five of the seven patients with alveolitis had serum precipitins (table 1).

\section{Dose of antigen}

The maximum concentration of antigen nebulised in each case never exceeded $10 \mathrm{mg} / \mathrm{ml}$ in Coca's solution $(10 \%$ solution in the case of mammalian serum). In only four cases was this concentration nebulised for more than five minutes, and in each case the subject under investigation developed the

Table 2 A comparison of skin prick reactions to "specific" test material in 37 atopic and non-atopic subjects undergoing bronchial provocation. Atopic subjects with positive skin prick to specific material show the most pronounced tendency to develop asthma

\begin{tabular}{|c|c|c|c|c|c|}
\hline \multicolumn{2}{|l|}{ Inhalation test } & \multicolumn{2}{|c|}{ Prick positive } & \multicolumn{2}{|c|}{ Prick negative } \\
\hline No of patients & Reaction & Atopic & Non-atopic & Atopic & Non-atopic \\
\hline $\begin{array}{c}24 \\
(6) \\
1 \\
12\end{array}$ & $\begin{array}{l}\text { Asthma } \\
\text { Asthma and alveolitis } \\
\text { Alveolitis } \\
\text { None }\end{array}$ & $\begin{array}{r}14 \\
2 \\
1 \\
2\end{array}$ & $\begin{array}{l}4 \\
1 \\
-\end{array}$ & $\begin{array}{l}2 \\
\frac{1}{3}\end{array}$ & $\begin{array}{l}4 \\
\frac{2}{7}\end{array}$ \\
\hline
\end{tabular}


signs and symptoms of alveolitis; two were sensitive to $M$ faeni, one to Merulius lacrymans, and one to rat serum. Two patients reacted to a concentration of $0.1 \mathrm{mg} / \mathrm{ml}$ nebulised for five minutes or less, 10 to a concentration of $1.0 \mathrm{mg} / \mathrm{ml}$, nine to $10 \mathrm{mg} / \mathrm{ml}$, and four to a concentration of $10 \mathrm{mg} / \mathrm{ml}$ nebulised for up to 30 minutes in one case and 15 minutes in three. Inhalation of larger doses of antigen provoked alveolitic reactions.

\section{Discussion}

Bronchial provocation testing with soluble allergens is safe, provided that a careful procedure is followed, and offers supporting evidence for identifying the cause of the respiratory disease. ${ }^{1}$ Selection of a safe starting concentration of nebulised allergen based on skin prick test is reliable. Nevertheless, testing in this way has important disadvantages. It is timeconsuming and removes the patient from his place of work for a week at least. Though it is safe, it is invasive and may not exactly mimic the conditions of exposure. Of 37 patients thought to suffer occupationally related disease on the basis of history alone, $24(65 \%)$ had a positive bronchial provocation test. The most discriminating test was the skin prick test with the suspected antigen and in only two out of $13(15 \%)$ was this test negative.

Earlier work from this department has shown that allergens derived from the urine of rats and mice were more reactive than serum or extract of dander. ${ }^{6}$ One laboratory worker showed much greater reaction to urine extracts from five-month-old Sprague Dawley rats than urine extracts from the six-week-old rats at the same concentration. The older rats produce urine containing more protein and so exposure to antigen is likely to be greater. In addition extracts from male rats contain larger quantities of protein than extracts from females.

The major source of antigen in rabbits and guinea pigs is also derived from the urine rather than skin serum or dander, and this may be true of yet other animal species.

We have seen several farmers who wheeze on contact with pigs. One farmer tested wheezed on contact with the pig in the laboratory, but not when exposed to the nebulised urine extract. The antigens responsible have not yet been identified.

Extrinsic allergic alveolitis is usually diagnosed from the history and appropriate changes on chest radiographs and is supported by finding precipitating antibody in the serum. We only attempted provocation testing when the diagnosis lay in doubt. For example, the diagnosis of bird fancier's lung and farmer's lung was confirmed in some patients when the precipitin tests were negative immediately before challenge, or when the chest radiograph looked normal.

Frequent and prolonged measurement of peak flow rate at home and at work has shown various patterns of occupational asthma, and positive work records measured in this way correlate well with bronchial provocation testing. ${ }^{7}$ Until the use of peak flow records is accepted as a discriminating test of occupational asthma, bronchial provocation testing will continue to provide a highly specific but expensive diagnostic tool, but the diagnosis of "allergic alveolitis" with a normal chest radiograph and characteristic changes in pulmonary physiology can be made only by provocation testing.

\section{References}

${ }^{1}$ Pepys J, Hutchcroft BJ. Bronchial provocation tests in aetiological diagnosis and analysis of asthma. Am Rev Respir Dis 1975;112:829-59.

${ }^{2}$ Newman Taylor AJ, Davies RJ, Hendrick DJ, Pepys J. Recurrent nocturnal asthmatic reactions to bronchial provocation tests. Clin Allergy 1979;9:213-9.

${ }^{3}$ Pepys J. Hypersensitivity disease of the lungs due to fungi and organic dusts. Monographs in allergy. Basel: Karger, 1969.

${ }^{4}$ O'Brien IM, Bull J, Creamer B, et al. Asthma and extrinsic allergic alveolitis due to Merulius lacrymans. Clin Allergy 1978;8:535-42.

5 Burge PS, O'Brien IM, Harries MG, Pepys J. Occupational asthma due to inhaled carmine. Clin Allergy 1979;9: 185-9.

${ }^{6}$ Newman Taylor AJ, Longbottom JL, Pepys J. Respiratory allergy to urine proteins of rats and mice. Lancet 1977;ii: 847-9.

7 Burge PS, O'Brien IM, Harries MG. Peak flow rate records in the diagnosis of occupational asthma due to colophony. Thorax 1979;34:308-16. 